\title{
Alejandro E. Parada, Lectura y contralectura en la Historia de la Lectura, Villa María, Eduvim, 2019, 120 pp.
}

\author{
Martín Ezequiel Calabrese \\ Instituto de Investigaciones en Humanidades y Ciencias Sociales, \\ Universidad Nacional de La Plata-CONICET, Argentina
}

Cita sugerida: Calabrese, M. E. (2020). [Revisión del libro Lectura

y contralectura en la Historia de la Lectura por A. E. Parada].

Olivar, 20(32), e088. https://doi.org/10.24215/18524478e088

El libro de Alejandro Parada logra abordar desde una pluralidad de ángulos esta disciplina que se ha ganado lugar indiscutible y una presencia desbordante en la Nueva Historia de la Cultura. Pretende, con los ensayos que conforman el libro, funcionar como hoja de ruta para poder tener una visión general de este territorio disciplinar con múltiples y variados paisajes.

Fiel al rigor metodológico y a la minuciosidad con que ha realizado otras publicaciones, Alejandro Parada da cuenta en este volumen de las cuantiosas ramificaciones y aristas de la Historia de la Lectura, disciplina que en pocas décadas ha mutado y se ha afianzado en su heterogeneidad. El foco, sin embargo, está puesto en la bibliografía que circula en castellano, ya que se presenta como un volumen destinado a la enseñanza en el ámbito latinoamericano. Se plantea como una recopilación, pero no deja de ser una apasionada invitación a la reflexión que evidencia las dificultades y las zonas grises del objeto que pretende denominar.

Es una obra pensada como un primer acercamiento al tema, aunque da cuenta en sus referencias bibliográficas de un basto panorama en el campo del conocimiento, aunque la humildad del autor la define como "obra selectiva y parcial en cuanto a su contenido, y personalizada en las inquietudes del autor". El libro presenta, sin embargo, una gradualidad y una complejidad creciente. Se inicia con la aproximación a una definición del tema, que se reconoce como problemática e insuficiente; se señalan las dificultades de la misma y, por último, se abordan las complejas variables teóricas y casi meta-teóricas de la Historia del Libro, en los 
diferentes "paisajes" que circundan y extienden el tejido teórico, y posibilitan su renovada resignificación. El ensayo final agrupa y discute las contribuciones anteriores, deviene en conclusión del libro.

En la introducción, el autor da cuenta del objetivo que se propone, demostrando al mismo tiempo, una plena conciencia del momento y desde el lugar que escribe:

es necesario insistir en este punto: el libro ha sido planificado para debatir y discutir (no necesariamente para coincidir) en los contenidos que plantea y, ante todo, como se comentado, la tríada inicial representa discursos textuales cuya unidad o empleo autónomo puede resultar eficaz en el aula o como herramienta para la enseñanza a distancia. (12)

La problemática de la lectura ha interpelado al autor de múltiples formas. Recordemos que en un trabajo anterior, Cuando los lectores nos susurran (2017), Parada aborda de manera práctica varias de las facetas que teoriza en el presente, situándolas en el ámbito argentino, puntualizando en las bibliotecas; los libros y lectores en torno a la revolución de Mayo; los cambios en el lectorado en el siglo XX y el análisis en concreto de algunas representaciones editoriales del Quijote en nuestro país. En otra ocasión, en el año 2013, dirigió el libro Cruces y perspectivas de la cultura escrita Argentina, que nuclea 10 trabajos de diferentes autores sobre esta temática. De este modo podríamos situar a Alejandro Parada como uno de los referentes de la Historia de la Cultura Escrita Argentina, y el volumen que reseñamos como una revisión y posicionamiento en dicho campo de estudio.

Los tres primeros ensayos abordan diferentes facetas de la Historia de la Lectura mediante la reflexión teórica. El primer ensayo trata de establecer una definición mínima y provisional. Se presenta como una puerta de entrada para meditar con una base bibliográfica que da muestra de un conocimiento y una selección de los referentes teóricos más relevantes y, también, las complejidades de la definición del objeto. El segundo, trata de afrontar los enfoques menos conocidos. Desarrolla el concepto de "paisaje", préstamos del ámbito sociológico, para poder analizar la Historia de la Lectura desde otras aristas menos tradicionales. Delinea entonces: el paisaje local y global; el cognitivo y práctico; el emotivo-pasional; el teórico; el filosóficoepistemológico, racional e imaginativo; el crítico y el comparativo; el de mutación material; el biológico textual; la vinculación con la Bibliotecología y la Ciencia de la Información; la documentación Archivología y Museología; los paradigmas lectores. El tercero es una continuación, y trata de pensar a los lectores y sus lecturas desde dimensiones impensadas, tensando y desbordando el objeto, con un matiz más hipotético. Vuelve a poner el foco en esa entidad biológica que denominamos los lectores. Lo más interesante de este ensayo es retomar el método planteado por Carlo Ginzburg en El queso y los gusanos (1976): "el 'método indiciario' [que] consiste en buscar las 'huellas' testimoniales a través de un proceso de interpretación y así establecer una serie de 'indicios' factibles de ser elevados a la categoría de hechos (p 71). El historiador de la lectura debe tener presente que su trabajo tiene algo de hipotético, ya que los materiales con los que trabaja plantean un camino, pero no del todo señalizado; más bien plantean un camino a tientas.

La Historia de la Lectura, entonces, se sitúa en el área de la Nueva Historia Cultural, en un campo de la historia de la Cultura Escrita, y su objetivo se centra en estudiar las representaciones, prácticas, usos, apropiaciones y respuestas de los lectores frente a los discursos de los textos en el pasado -cualesquiera sean sus soportes y manifestaciones de escritura-, y que ocasionaron cambios en sus modos de pensar y accionar en el mundo (tanto reales como imaginarios). Esa es la captura histórica de los lectores en el tiempo.

En la conclusión de su libro, presente en el volumen como un cuarto ensayo, retoma la complejidad de esta tarea, plantea que es difícil arribar a una conclusión y esto se debe:

a) a su vocación multidisciplinar, que escapa a un solo alineamiento de comprensión;

b) a que la mayoría de los autores conciben el "entramado lector-soporte-práctica y apropiación” desde lados dispares;

c) a que dichos estudiosos tampoco se han puesto de acuerdo en cómo denominar, en forma unívoca, a ese amplísimo e inasible territorio cultural;

d) a que toda esta situación trae como colación un serio escollo para su consolidación disciplinar. 
La imposibilidad, como plantea más abajo, se debe a lo inabarcable de la masa lectora. Sin embargo, lo que es posible, es analizar aquellos registros que se conservan de una pequeña porción de esos lectores, "las contadas personas que dejaron algún registro" en palabras de Darton (1990). El libro es una interesante puesta en discusión de una disciplina que, como todas en sus inicios, tiene más de práctica que de teoría. 